\title{
Consequences of early parental loss and separation for health and well-being in midlife
}

\author{
E. Hailey Maier and Margie E. Lachman \\ Brandeis University, Waltham, USA
}

\begin{abstract}
We examined the impact of parental death and divorce prior to age 17 on physical and mental wellbeing in a national probability sample of middle-aged adults. The results suggest that, for men, parental divorce was associated with less positive relations with others, less self-acceptance, lower environmental mastery, and greater depression. Parental divorce predicted higher levels of physical health problems for both men and women. This relationship was mediated by income, education, drug use, and family support and was greater for men than women. Parental death predicted more autonomy for men and a higher likelihood of depression for women. The results contribute to understanding the developmental pathways involved in linking early life experiences to adulthood outcomes.
\end{abstract}

The negative impact of parental death and divorce during childhood is well documented in the literature. However, less is known about the long-term consequences of childhood experiences on mid-life (Elder, George, \& Shanaham, 1996; Lachman \& James, 1997). Although relatively few studies have examined the long-term impact of early parental death, there is a fair amount of evidence to support the relationship between early parental death and certain types of psychopathology in adulthood (Berlinsky \& Biller, 1982). Parental divorce has been associated with various socioeconomic (SES) differences, behavioural problems, and personality changes in both childhood and adulthood (Amato \& Keith, 1991a). However, the long-term effect of parental separation on physical health has received far less attention.

Bowlby (1982) described the effect of parental loss in terms of both an increased likelihood of and a greater vulnerability to future adversity. This theory has been supported by research which clearly points to the circumstances following or preceding the loss as the main risk factor for the child (Rutter, 1995). Although parental separation does not necessarily lead to psychopathology, it may initiate a chain of negative events which causes its effect to persist over time. Because parental death or divorce causes a lasting change in the child's environment, it can be a turning point for certain individuals (Rutter, 1996). Wertlieb (1997, p.189) emphasised the need for researchers to identify the factors and mechanisms involved in a life change such as parental divorce "reaching the threshold of becoming a (transformational) turning point". The relative lack of research attempting to identify the pathways through which childhood adversity may have a long-term impact on development has been cited as a limitation of the existing literature in this area (Kessler, Gillis-light, Magee, Kendler, \& Eaves, 1997). The studies that have examined mediators of parents' death or divorce tend to be narrow in focus, often using only one outcome measure, or do not consider the long-term impact of such experiences (e.g. Brown \& Harris, 1978; Hetherington, 1989).
Recently, Tucker et al. (1997) examined the mediators of parental divorce and mortality rates in the Terman sample. The relationship appeared to be mediated by lower educational attainment, less involvement with service activities, and a greater likelihood of divorce. Although the sample used in this study was large, the participants were not representative of the population as the study was based on a sample of gifted children. Additionally, the Terman data is based on a cohort born in the 1920s when divorce was far less common than it is today. Therefore, the impact of parental divorce for those individuals may be very different than its effects on children and adults today. Thus, one goal was to examine whether the relationship between parental divorce and adult health is mediated by factors such as social involvement and educational attainment as Tucker et al.'s findings suggest.

According to the resources and stresses model (Amato, 1993) parental divorce impacts well-being by increasing the likelihood of other stressors, although certain protective resources may lessen the effect of these stressors. Parental death is also thought to increase the likelihood that an individual will encounter further adverse experiences (Bowlby, 1982). One way divorce and death lead to other life stresses is through a reduction in financial resources. Several studies have found that children who are separated from one parent during childhood tend to have lower income and education levels as adults (Amato \& Keith, 1991c). Not only do financial resources become limited, but the remaining parent may also have less time to help the children with their homework and take them to special lessons or activities. This may ultimately result in lower education and income attainment for the children. The relationship between SES and health is well supported in the literature (e.g. Marmot, Kogevinas, \& Elston, 1987), although the mechanisms behind this association are not yet understood. Lower income and education levels might impact health through a reduction in access to healthcare or through additional stress caused by a lack of financial resources. 
In addition, parental death and divorce may lead to a reduction in social support which is also related to poorer health (House, Umberson, \& Landis, 1988). Both death and divorce remove one parent from the home which limits the amount of parental support the child receives. Furthermore, both types of loss are associated with interpersonal difficulties which may reduce the amount of support the child later receives from friends or family. Bowlby (1977) suggested that parental death may impair the child's ability to form an image of him/herself as both capable of helping him/herself and deserving of help from others. Ragan and McGlashan (1986) found that participants who grew up in families where one or both parents died were more likely to have difficulty forming stable adult relationships. Clark and Clifford (1996) found that children whose parents divorced had higher levels of interpersonal dependence which had a detrimental effect on their social interactions. Several studies have reported higher divorce rates for adult children of divorce (Keith \& Finlay, 1988), and others have found that parental divorce is related to a lower probability of ever marrying (Amato \& Keith, 1991a). There is evidence that married people tend to have fewer health problems than single people do. Clearly, parental death and divorce have the potential to impact social relationships which otherwise might buffer the effects of future stresses.

Finally, parental death and divorce may also be associated with particular lifestyle changes that could affect physical health in mid-life. There is some evidence that parental death may increase the likelihood of alcohol and drug abuse in adulthood (Dennehy, 1966). Researchers have also found that substance use may increase in children after their parents divorce (Aro \& Palosaari, 1992; Doughtery \& Needle, 1991). The children may feel rejected by the nonresident parent and find comfort in peer groups that pressure him/her to use drugs, drink, or smoke. If these health-compromising behaviours continue into adulthood, they may also explain the impact of parental divorce on adult health.

The present study examined the impact of parental divorce and death on physical health in mid-life, and factors that may mediate this relationship. In addition, we looked at measures of psychological well-being and depression to examine the effects of parental separation on mental as well as physical health. It was hypothesised that those who experienced loss of either kind would score lower on the measures of well-being, and report higher levels of depression. Participants whose parents divorced were also expected to report a greater number of health problems. We predicted that the impact of parental separation on physical health would be mediated by SES factors (educational attainment, income, and marital history), behavioural factors such as substance abuse and smoking, and lower levels of social support.

\section{Method}

\section{Participants}

The sample consisted of 4242 adults who responded to the survey of Midlife Development in the US (MIDUS) conducted by the John D. and Catherine T. MacArthur Foundation Network on Successful Midlife Development in 1995. This national probability sample (MIDUS) was selected using random digit dialling. Participants were interviewed on the telephone for $20-30$ minutes ( $70 \%$ response rate) and then sent a two-booklet questionnaire through the mail (completed by $87 \%$ of the telephone sample).

The respondents were from 24 to 74 years old $(M=46.43$, $\mathrm{SD}=13.36)$, but only those between the ages of 30 and $60(M$ $=44.33, \mathrm{SD}=8.71)$ were analysed in the present study to limit the focus to midlife $(N=2988)$. The sample was $49 \%$ male, and $89 \%$ were Caucasian. For the sample overall, $11 \%$ had less than a high school degree, $29 \%$ had completed high school or equivalent, $31 \%$ had completed some college, and $29 \%$ had a baccalauréat or advanced degree.

\section{Measures of mental health}

Well-being. Psychological well-being was measured using 18 items from the Ryff (1989) scales. The six scales were designed to assess positive relations with others (coefficient alpha $=.58$ ), self-acceptance (coefficient alpha $=.59)$, autonomy $($ coefficient alpha $=.48)$, personal growth $($ coefficient alpha $=.55)$, environmental mastery (coefficient alpha $=.52$ ), and purpose in life (coefficient alpha $=.36$ ) (Ryff \& Keyes, 1995). Examples of the items include "maintaining close relationships has been difficult and frustrating to me" (positive relations with others) and "I have confidence in my own opinions even if they are different from the way most other people think" (autonomy). All scales were assessed with three items on a 7point scale. The items were reverse scored, and the mean was taken for each scale. Higher scores indicate higher levels of a particular attribute (i.e. more autonomy, more self-acceptance, greater sense of purpose in life).

Depression. This was assessed using Kessler and Mroczek's dichotomous diagnostic depression variable used in the national Comorbidity Study (Kessler et al., 1996). Participants were asked if there was a time when they felt sad, blue, or depressed for two weeks or more in a row during the past 12 months. If they did, and felt that way for all or most of the day during those two weeks, they were asked nine "yes" or "no" questions about their feelings. Examples of these questions include, "during those two weeks, did you lose your appetite?" and "did you think about death a lot during those two weeks?' The respondents were also asked whether they ever lost interest in most things that usually given them pleasure for two weeks or more during the last 12 months. Those that did and felt that way all day or most of the day were asked the same nine questions. The participants who said "yes" to three or more of the questions in either set were classified as depressed $(0=$ not depressed, $1=$ depressed $)$.

\section{Measures of physical health}

Physical health was assessed with indicators of acute and chronic health problems. For chronic health problems, participants rated whether or not they had experienced or been treated for 28 health problems (e.g. tuberculosis, hypertension, asthma) in the past year. A total score was computed based on the number of chronic health problems participants endorsed. For acute health problems, respondents indicated how often they experienced each of nine psychophysical symptoms in the past 30 days on a 6-point scale. Examples of acute health problems are headaches, hot flushes, sweating a lot, and trouble getting to sleep. Higher scores on both scales reflect more health problems. 


\section{Potential mediators}

Education level was measured by one question which asked respondents to indicate the number of years of education they had completed. The total household income of each participant was measured on a 7 -point scale with 1 representing $\$ 0$ to $\$ 9999$ and 7 representing $\$ 50,000$ and over. The participant's marital status was represented by a dichotomous variable where 1 = married, 2 = all other responses (separated, divorced, widowed, never married).

The items used to assess drug and alcohol use were based on the World Health Organisation's Composite International Diagnostic Interview. Respondents were asked to indicate whether they had used any of 10 types of drugs on their own in the past 12 months. They were told that "on your own" means either without a doctor's prescription, in larger amounts than prescribed, or for a longer period than prescribed. Examples of the types of drugs listed include sedatives, prescription painkillers, inhalents, and hallucinogens. Participants who answered yes to any of the 10 items were classified as using drugs $(0=$ does not use drugs, $1=$ uses drugs $)$. Smoking was measured by a dichotomous variable where $1=$ smokers and 2 $=$ nonsmokers.

Alcohol abuse was measured with two items which were "during the past 12 months, how many times did you use much larger amounts of alcohol than you intended to when you began, or used them for a longer period of time than you intended to?" and "in the past 12 months, how many times have you been under the effects of alcohol or suffering its aftereffects while at work or school, or while taking care of children?" The participants responded to these items on a 6point scale ranging where $1=$ "never" and $6=$ "more than 20 times". Based on the distribution of these items, a dichotomous variable was created where $1=$ never abused alcohol and $2=$ abused alcohol once or more.

The assessment of social support was examined for the following relationships: family support, friend support, and spouse/partner support. All items were answered on a 4-point Likert-type scale $(1=\mathrm{a}$ lot; $4=$ not at all $)$. Items were recoded so that higher scores reflected higher support. Supportive network interactions were measured through four items that were parallel for spouse/partner, family members, and friends. The four items were: (a) How much do they (family members, friends, spouse/partner) understand the way you feel about things? (b) How much do they really care about you? (c) How much can you rely on them for help if you have a serious problem? (d) How much can you open up to them if you need to talk about your worries? Two additional items were included for the domain of spouse/partner: How much does your partner or spouse appreciate you? and How much can you relax and be yourself around him or her?

\section{Measures of Parental Loss and Separation}

Participants were asked if they lived with both of their biological parents until they were 17 years old. If they did not, they were asked to indicate the reason for the separation and how old they were when it occurred. There were 173 men and 207 women in the sample who reported that their parents divorced before they were 17. Eighty-nine men and 93 women reported that either their mother or father died before they were 17 . The number of years since this event occurred ranged from 15 to 60 for men $(M=36.28, \mathrm{SD}=10.55)$ and 17 to 58 for women $(M=36.02, \mathrm{SD}=10.67)$. For each type of loss or separation, a dummy variable was created. For parental divorce, those who reported that their parents divorced were coded as 1 and all other participants received a zero for this variable. For parental death, respondents who reported that either their mother or their father died before they were 17 were coded as 1 and all others were coded as zero.

\section{Results}

A series of multiple regression equations were estimated to examine the effects of parental divorce and parental death on physical and mental well-being. Age was controlled in all analyses and models were estimated separately for men and women. Parental death and parental divorce were entered as a set of dummy variables so that participants who experienced either type of loss would be compared to respondents from intact families. The means and standard deviations of each variable for which significant differences were found appear in Table 1. In Table 2, correlations for all variables are presented for men, below the diagonal, and above the diagonal for women.

For the men, parental divorce significantly predicted lower levels of self-acceptance $\left[F(3,1284)=2.94, P<.03, R^{2}=\right.$ $.01]$, positive relations with others $[F(3,1286)=5.29, P<$ $\left..001, R^{2}=.01\right]$, and environmental mastery $[F(3,1285)=$ $\left.2.62, P<.05, R^{2}=.01\right]$, as well as higher numbers of acute $\left[F(3,1288)=2.30, P<.07, R^{2}=.01\right]$ and chronic $[F(3,1289)$ $\left.=15.86, P<.001, R^{2}=.04\right]$ health problems (see Table 1$)$. Men whose parents divorced were almost twice as likely to be classified as depressed $[\operatorname{Exp}(\beta)=1.96, P<.01]$ (see Figure $1)$. For the women in the sample, parental divorce was not significantly related to any of the psychological measures. However, women whose parents divorced before they were 17 did report significantly higher levels of acute health problems $\left[F(3,1315)=7.62, P<.001, R^{2}=.02\right]$.

Parental death did not predict either type of health problems for men or women. For men, parental death predicted higher levels of autonomy (see Table 1). Women who reported losing a parent through death were more likely to be depressed $[\operatorname{Exp}(\beta)=1.77, P<.05]$ compared to other women in the sample (Figure 1).

The hypothesised mediators between parental divorce and health problems were tested using the method recommended by Baron and Kenny (1986). Regression equations were estimated to examine the impact of parental divorce on each mediator. Parental divorce significantly predicted lower levels of education and family support for both sexes and income only for women (Table 3). Logistic regression analysis indicted that for men parental divorce is associated with a greater probability of drug use $[\operatorname{Exp}(\beta)=1.61, P<.001]$ and smoking $[\operatorname{Exp}(\beta)=.60, P<.01]$. Parental divorce was also associated with drug use $[\operatorname{Exp}(\beta)=1.70, P<.001]$ and smoking $[\operatorname{Exp}(\beta)=.45, P<.001]$ for women. None of the equations were significant for friend support, partner support, marital status, or alcohol abuse.

The last step to test mediators involves entering the potential mediator variables significant in the previous step (education, income, smoking, drug use, and family support) along with the independent variables to predict each outcome. All equations controlled for the effects of age at assessment. Drug use, education, income, and family support were still 
Table 1

Means (and standard deviations) or frequencies of variables significantly predicted by parental divorce or parental death

\begin{tabular}{llcrr}
\hline & & & & \\
& & Parental Divorce & Parental Death & \multicolumn{1}{c}{ Family } \\
\hline Chronic problems & $\mathrm{M}$ & $2.33(2.45)^{* * *}$ & $2.60(3.06)$ & $1.96(2.13)$ \\
& $\mathrm{W}$ & $2.72(2.71)$ & $2.60(2.23)$ & $2.55(2.56)$ \\
Acute problems & $\mathrm{M}$ & $9.36(6.67)^{*}$ & $8.46(6.93)$ & $7.97(6.53)$ \\
& $\mathrm{W}$ & $11.29(8.26)^{*}$ & $10.54(7.85)$ & $10.41(7.98)$ \\
Self-acceptance & $\mathrm{M}$ & $5.39(1.14)^{*}$ & $5.48(1.00)$ & $5.62(1.15)$ \\
& $\mathrm{W}$ & $5.24(1.24)$ & $5.43(1.24)$ & $5.42(1.16)$ \\
Positive relations & $\mathrm{M}$ & $4.94(1.40)^{* * *}$ & $5.16(1.38)$ & $5.32(1.36)$ \\
with others & $\mathrm{W}$ & $5.30(1.39)$ & $5.56(1.45)$ & $5.46(1.35)$ \\
Environmental & $\mathrm{M}$ & $5.24(1.15)^{*}$ & $5.55(1.10)$ & $5.47(1.11)$ \\
mastery & $\mathrm{W}$ & $5.26(1.19)$ & $5.38(1.20)$ & $5.24(1.56)$ \\
Autonomy & $\mathrm{M}$ & $5.57(0.95)$ & $5.78(0.97)^{*}$ & $5.56(1.07)$ \\
& $\mathrm{W}$ & $5.44(1.13)$ & $5.67(1.05)$ & $5.41(1.16)$ \\
Education & $\mathrm{M}$ & $6.55(2.42)^{*}$ & $6.20(2.44)^{* * *}$ & $7.17(2.66)$ \\
& $\mathrm{W}$ & $6.29(2.20)^{* *}$ & $6.42(2.40)$ & $6.61(2.42)$ \\
Income & $\mathrm{M}$ & $5.57(1.82)$ & $5.92(1.47)$ & $5.83(1.63)$ \\
& $\mathrm{W}$ & $5.00(1.98)^{* *}$ & $4.89(2.00)$ & $5.20(1.96)$ \\
Family support & $\mathrm{M}$ & $3.20(0.68)^{* * *}$ & $3.26(0.74)^{* *}$ & $3.41(0.61)$ \\
& $\mathrm{W}$ & $3.33(0.73)^{*}$ & $3.48(0.58)$ & $3.47(0.60)$ \\
Marriage & $\mathrm{M}$ & $13 \%$ & $18 \%$ & $13 \%$ \\
(\% not married) & $\mathrm{W}$ & $24 \%$ & $16 \%$ & $14 \%$ \\
Drugs (\% yes) & $\mathrm{M}$ & $21 \% * * *$ & $9 \%$ & $13 \%$ \\
& $\mathrm{~W}$ & $15 \% * * *$ & $9 \%$ & $11 \%$ \\
Smokes (\% yes) & $\mathrm{M}$ & $38 \% * *$ & $34 \%$ & $28 \%$ \\
Depression (\% yes) & $\mathrm{W}$ & $49 \% * * *$ & $41 \%$ & $28 \%$ \\
& $\mathrm{M}$ & $19 \% * *$ & $26 \%$ & $10 \%$ \\
\hline & $\mathrm{W}$ & $22 \%$ & & $17 \%$ \\
\hline
\end{tabular}

Note: $\mathrm{M}$, men; $\mathrm{W}$, women. ${ }^{*} P<.05 ; * * P<.01 ; * * P<.001$.

significantly predictive of acute health problems for women $(F$ $=26.29, P<.0001)$. Parental divorce was no longer significant in this equation, providing support for mediation. Smoking was not significantly related to either type of health problem for men or women. For men, both chronic $(F=$ 19.39, $P<.0001)$ and acute health problems $(12.44, P<$
.0001 ) were predicted by education, drug use, and family support (Table 4). Although parental divorce still significantly predicted chronic health problems, the effect was reduced when drug use, education, and family support were included in the equation which is indicative of mediation (Baron \& Kenny, 1986).

Table 2

Correlations among variables

\begin{tabular}{|c|c|c|c|c|c|c|c|c|c|c|c|c|c|c|c|c|c|}
\hline & 1 & 2 & 3 & 4 & 5 & 6 & 7 & 8 & 9 & 10 & 11 & 12 & 13 & 14 & 15 & 16 & 17 \\
\hline 1 Age & - & .05 & -.04 & -.03 & $.20 * *$ & .03 & .04 & .04 & .05 & .03 & $-.14 * *$ & $.09 * *$ & .00 & $.07 * *$ & $-.11 * *$ & $-.12 * *$ & $-.08 * *$ \\
\hline 2 Parental death & $.09 * *$ & - & -.09 & -.01 & .04 & -.02 & -.03 & .02 & $.07 *$ & -.03 & -.03 & .01 & $-.11 * *$ & $-.07 *$ & .05 & -.01 & .04 \\
\hline 3 Parental divorce & $-.11 * *$ & $-.10^{* *}$ & - & $.07 *$ & $.10^{* *}$ & $-.07 *$ & $-.10 * *$ & $.06^{*}$ & .00 & $.08 * *$ & $.08 * *$ & -.05 & $.05 *$ & $-.10 * *$ & .03 & $.06^{*}$ & $.09 * *$ \\
\hline 4 Acute problems & $.12 * *$ & .01 & .04 & - & $.46 * *$ & $-.31 * *$ & $-.25 * *$ & $-.35 * *$ & $.12 * *$ & $-.06 *$ & $.20 * *$ & $-.19 * *$ & $-.13 * *$ & $-.18 * *$ & .03 & $.13^{* *}$ & $.22 * *$ \\
\hline 5 Chronic problems & $.17 * *$ & -.03 & .04 & $.54 * *$ & - & $-.23 * *$ & $-.20 * *$ & $-.23 * *$ & $-.10^{* *}$ & -.04 & $.14 * *$ & $-.14 * *$ & $-.13 * *$ & $-.10 * *$ & .05 & .01 & $.17 * *$ \\
\hline 6 Self-acceptance & $.07 *$ & $.06 *$ & -.05 & $-.33 * *$ & $-.21 * *$ & - & $.50 * *$ & $.58 * *$ & $.24 * *$ & $.13 * *$ & $-.12 * *$ & $.23 * *$ & $.13 * *$ & $.29 * *$ & -.21 & $.13 * *$ & $-.22 * *$ \\
\hline 7 Positive relations & .05 & .04 & -.05 & $-.24 * *$ & $-.17 * *$ & $.49 * *$ & - & $.36^{* *}$ & $.17^{* *}$ & $.08^{*}$ & $-.13 * *$ & $.17 * *$ & $.07 * *$ & $.34 * *$ & -.24 & $-.14 * *$ & $-.15 * *$ \\
\hline $\begin{array}{l}8 \text { Environmental } \\
\text { mastery }\end{array}$ & .05 & .04 & -.01 & $-.34 * *$ & $-.20^{* *}$ & $-.57 * *$ & $.39 * *$ & - & $.28 * *$ & $.14 * *$ & $-.16 * *$ & $.16^{* *}$ & $.08 * *$ & $.27 * *$ & -.08 & -.11 & $-.21 * *$ \\
\hline 9 Autonomy & $.13 * *$ & .04 & .02 & $-.09 * *$ & $-.07 * *$ & $.31 * *$ & $.26 * *$ & $.36 * *$ & - & .02 & -.02 & $.07 *$ & -.02 & $.10^{* *}$ & .00 & $-.07 *$ & $-.08 * *$ \\
\hline 10 Smoking & $.12 * *$ & -.06 & $-.16^{* *}$ & $-.09 * *$ & $-.08^{*}$ & -.06 & .06 & .00 & $-.07 *$ & - & $-.10 * *$ & $.12 * *$ & $.27 * *$ & .03 & -.12 & $-.12 * *$ & $-.11 * *$ \\
\hline 11 Drug use & $-.08 * *$ & .01 & $.07 * *$ & $.17 * *$ & $.16^{* *}$ & $-.12 * *$ & $-.12 * *$ & $-.13 * *$ & -.01 & $-.11 * *$ & - & $-.09 * *$ & .01 & $-.12 * *$ & .11 & $.18^{* *}$ & $.11 * *$ \\
\hline 12 Income & -.01 & -.01 & $-.07 * *$ & $-.15 * *$ & $-.12 * *$ & $.23 * *$ & $.18 * *$ & $.11 * *$ & -.01 & $.22 * *$ & $-.06 *$ & - & $.28 * *$ & $.09 * *$ & -.32 & .01 & $-.16 * *$ \\
\hline 13 Education & -.03 & .01 & $-.08 * *$ & $-.18 * *$ & $-.10 * *$ & $.21 * *$ & $.12 * *$ & $.11 * *$ & .01 & $.23^{* *}$ & -.02 & $.34 * *$ & - & .04 & -.00 & .03 & -.04 \\
\hline 14 Family support & $.10 * *$ & -.00 & $.07 *$ & $-.17 * *$ & $-.08 * *$ & $.29 * *$ & $.35 * *$ & $.25 * *$ & $.12 * *$ & -.00 & -.04 & $-.09 * *$ & .04 & - & $-.11 * *$ & -.05 & $-.10 * *$ \\
\hline 15 Marital status & .01 & .00 & .02 & .03 & .05 & $-.13 * *$ & $-.18 * *$ & -.00 & $.06^{* *}$ & $-.18 * *$ & $.07 * *$ & $-.48 * *$ & -.02 & $-.12 * *$ & - & $.12 * *$ & $.14 * *$ \\
\hline 16 Alcohol abuse & $.08 * *$ & .02 & -.00 & $.09 * *$ & .01 & -.01 & .01 & -.03 & -.02 & -.13 & .13 & .01 & .06 & -.01 & $.12 * *$ & - & $.10 * *$ \\
\hline 17 Depression & $-.08 * *$ & $.05 *$ & .04 & $.29 * *$ & $.20 * *$ & $-.25 * *$ & $-.20 * *$ & $-.25^{* *}$ & $-.06^{*}$ & $-.08 * *$ & .12 & $-.10 * *$ & -.05 & $.15 * *$ & $.12 * *$ & $.06 *$ & - \\
\hline
\end{tabular}

Note: Parental death: $0=$ no, $1=$ yes; Parental divorce: $0=$ no, $1=$ yes; Smoker: $1=$ smoker, $2=$ nonsmoker; Drug use: $0=$ no, $1=$ yes; Alcohol abuse: $0=$ no, $1=$ yes; Depression: $0=$ no, $1=$ yes; Marital status: $1=$ married, $2=$ not married. Men above diagonal; Women below diagonal.

$* P<.05 ; * P<.01$ 


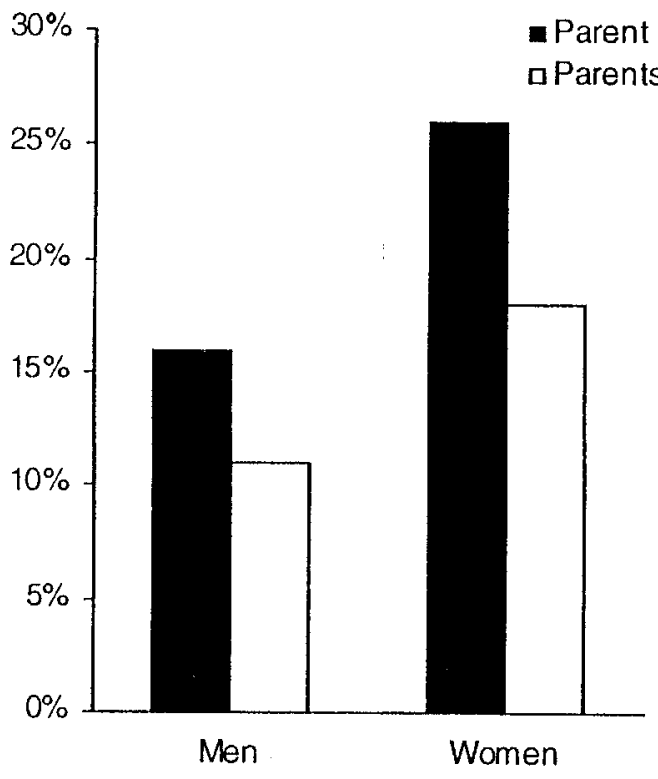

Parental Death

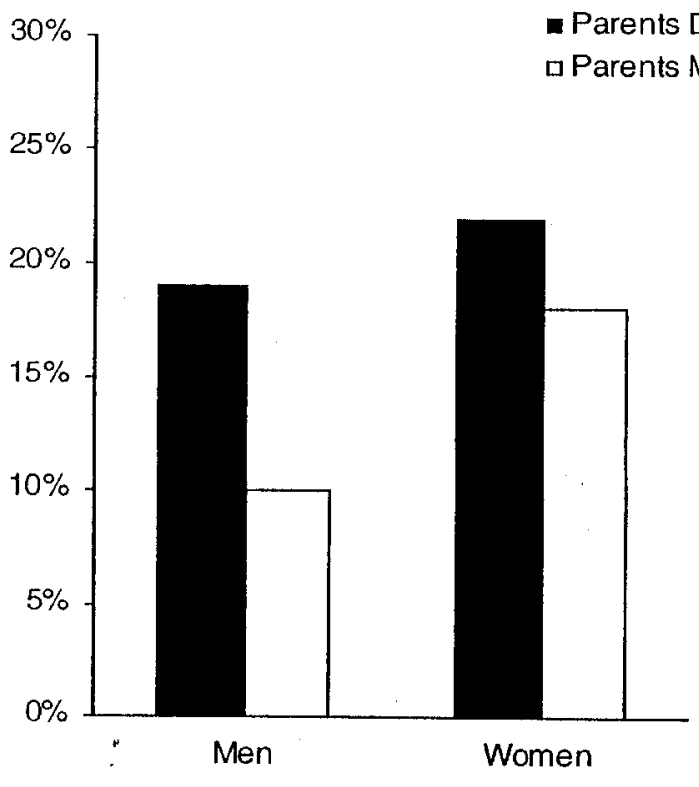

Parental Divorce

Figure 1. Percentage depressed by sex and type of loss.

Table 3

Regression equations predicting education, income, and family support

\begin{tabular}{|c|c|c|c|c|c|c|c|c|c|c|}
\hline & \multicolumn{4}{|c|}{ Men } & \multicolumn{6}{|c|}{ Women } \\
\hline & \multicolumn{2}{|c|}{ Education $^{\mathrm{a}}$} & \multicolumn{2}{|c|}{$\begin{array}{l}\text { Family } \\
\text { Support }^{\mathrm{b}}\end{array}$} & \multicolumn{2}{|c|}{ Education $^{\mathrm{c}}$} & \multicolumn{2}{|c|}{ Income $^{\mathrm{d}}$} & \multicolumn{2}{|c|}{$\begin{array}{l}\text { Family } \\
\text { Support }^{\mathrm{e}}\end{array}$} \\
\hline & $\mathrm{B}$ & SE B & B & SE B & B & SE B & $\mathrm{B}$ & SE B & B & SE B \\
\hline Age & .00 & .01 & $.01 * *$ & .01 & -.01 & .01 & -.00 & .01 & $.01 * *$ & .00 \\
\hline Parental divorce & $-.53 *$ & .21 & $-.22 * * *$ & .06 & $-.58 *$ & .18 & $-.41 * *$ & .15 & $-.11 *$ & .05 \\
\hline Parental death & $-.13 * * *$ & .28 & $-.24 * *$ & .08 & .09 & .26 & -.11 & .21 & -.04 & .07 \\
\hline
\end{tabular}

Note: ${ }^{\mathrm{a}} R^{2}=.02(P<.0001) .{ }^{\mathrm{b}} R^{2}=.02(P<.0001) .{ }^{\mathrm{c}} R^{2}=.01(P<.01) .{ }^{\mathrm{d}} R^{2}=.01(P=.056) .{ }^{\mathrm{e}} R^{2}=.01(P<.0001)$.

$* P<.05 ; * * P<.02 ; * * * P<.001$.

Table 4

Final regression equations predicting acute and chronic health problems

\begin{tabular}{|c|c|c|c|c|c|c|c|c|c|c|c|c|}
\hline & \multicolumn{8}{|c|}{ Men } & \multicolumn{4}{|c|}{ Women } \\
\hline & \multicolumn{2}{|c|}{$\begin{array}{c}\text { Acute } \\
\text { Problems }\end{array}$} & \multicolumn{2}{|c|}{$\begin{array}{c}\text { Acute } \\
\text { Problems }\end{array}$} & \multicolumn{2}{|c|}{$\begin{array}{l}\text { Chronic } \\
\text { Problems }\end{array}$} & \multicolumn{2}{|c|}{$\begin{array}{l}\text { Chronic } \\
\text { Problems }^{\mathrm{d}}\end{array}$} & \multicolumn{2}{|c|}{$\begin{array}{c}\text { Acute } \\
\text { Problems }\end{array}$} & \multicolumn{2}{|c|}{$\begin{array}{c}\text { Acute } \\
\text { Problems }\end{array}$} \\
\hline & $\mathrm{B}$ & SE B & $\mathrm{B}$ & SE B & B & SE B & $\mathrm{B}$ & SE B & $\mathrm{B}$ & SE B & $\mathrm{B}$ & SE B \\
\hline Age & -.02 & .02 & .00 & .02 & $.05 * * *$ & .01 & $.06 * * *$ & .01 & $.11 * * *$ & .02 & $.13 * * *$ & .03 \\
\hline Parental divorce & $1.38 *$ & .58 & .39 & .63 & $.72 * * *$ & .21 & $.51 *$ & .21 & $1.30 *$ & .64 & -.57 & .73 \\
\hline Parental death & -.18 & .81 & -.94 & .85 & .29 & .29 & .15 & .29 & -.33 & .89 & -.27 & 1.04 \\
\hline Education & & & $-.31 * * *$ & .08 & & & $-.11 * * *$ & .03 & & & $-.32 * *$ & .12 \\
\hline Income & & & & & & & & & & & $-.44 * *$ & .14 \\
\hline Family support & & & $-1.19 * * *$ & .31 & & & $.22 *$ & .10 & & & $-2.23 * * *$ & .40 \\
\hline Drug use & & & $3.05 * * *$ & .53 & & & $.99 * * *$ & .18 & & & $3.52 * * *$ & .70 \\
\hline Smoking & & & -.17 & .45 & & & .07 & .15 & & & -.80 & .56 \\
\hline
\end{tabular}

Note: ${ }^{\mathrm{a}} R^{2}=.02(P<.076) .{ }^{\mathrm{b}} R^{2}=.07(P<.0001) .{ }^{\mathrm{c}} R^{2}=.05(P<.0001) .{ }^{\mathrm{d}} R^{2}=.10(P<.0001) .{ }^{\mathrm{e}} R^{2}=.02(P<.0001) .{ }^{\mathrm{f}} R^{2}=.07$ $(P<.0001)$.

$* P<.05 ; * P<.01 ; * * * P<.001$. 


\section{Discussion}

The present study suggests that loss or separation from parents in childhood does have a negative impact on health problems and psychological adjustment in midlife and that the effects are more pronounced for divorce. It appears that parental divorce leads to lower education and income attainment, an increase in drug use, and lower levels of family support which may result in a greater number of health problems later in life.

The finding that early parental divorce has a greater impact on men than women is consistent with previous research. Tucker et al. (1997) found that mortality rates were higher for men whose parents divorced, but for women this was only a trend. Other researchers have found that parental divorce was related to the probability of ever marrying for men, but not for women (Keith \& Finlay, 1988). Doherty and Needle (1991) found that externalising behaviours, such as substance abuse, increase more for boys than for girls following parental divorce. They also found that boys' self-esteem was reduced more than girls' which is consistent with the effect on self-acceptance in the present study. Hetherington (1989) reported that the children she classified as "winners" following their parents' divorce were almost all girls and those in the "losers" group were more likely to be boys.

The literature also supports the finding that there is a stronger effect of parental divorce than for parental death in mid-life. Tennant (1988) found no effect of parental death on adult health. Schwartz et al. (1995) examined the effect of both parental divorce and death on longevity and found that there was an effect of divorce, but not bereavement. A meta-analysis analysing the impact of parental divorce on the well-being of children revealed that children of divorce have lower levels of well-being than children who lose a parent through death (Amato \& Keith, 1991b).

According to the resources and stresses model (Amato, 1993), divorce impacts well-being through increasing the likelihood of future stresses, but certain resources, such as social support, may minimise these negative effects (Emery \& Forehand, 1994). The participants whose parents had divorced had lower income and educational attainment which is likely to engender multiple stresses associated with lower SES. However, parental death was also related to lower educational attainment, but showed no relationship to adult health. Although both experiences can impact economic resources, social resources may be more affected by parental divorce. Parental divorce can result in changes in the child's relationship with both parents whereas parental death is less likely to disrupt the child's relationship with the remaining parent. As a good relationship with one parent can be protective for children in certain circumstances (Rutter, 1990), it may be that divorce has a stronger effect in mid-life because it carries with it a higher likelihood of not having a supportive relationship with either parent (Glenn \& Kramer, 1985).

Clark and Clifford, whose study was based on the resources and stressors model proposed by Amato (1993), found that the "family climate" was particularly important in determining the impact of parental divorce. They also found that men are especially vulnerable to emotional distance and lack of supportiveness. Other researchers have found that the relationship between social support and health is stronger for men. Therefore, if divorce affects adult health through disrupting future relationships, this could explain the stronger effect for men than women.
Although less numerous, the effects of parental death on well-being in mid-life were also interesting. Indeed, we found that men who lost a parent through death before the age of 17 were more autonomous than other men in the sample. Researchers have suggested that children who grow up in a single-parent household may perceive their parents as less controlling, and the child may become more responsible or autonomous (Weiss, 1979). However, these men were not necessarily all raised in single-parent households. Other studies have found that parental separation for either reason may force early entry into social roles which may in turn increase the children's independence and sense of self-reliance (Amato \& Keith, 1991).

Analysis of the relationship between parental separation and depression also produced some interesting results. The relationship between parental death and depression for young women found in other studies (e.g. Brown, 1981) was replicated in this sample. However, for parental divorce, it was the men who were almost twice as likely to be depressed compared to other men in the sample. In a meta-analysis, Amato and Keith (1991a) found no sex differences in the relationship between parental divorce and psychological adjustment. Further research is necessary to examine how parental divorce may differentially affect men and women.

Neither parental divorce nor parental death predicted alcohol abuse or marital status, although some past studies have found evidence of such effects. The variable used to measure alcohol abuse in our sample was based on questions pertaining to the participants' drinking patterns within the past year. A measure of lifelong alcohol use may have produced different results. To further assess the relationship between parental separation and marital status we divided the participants who were not married into two different groups: those who had never been married and those who had been married in the past, but were currently divorced or separated. The most striking difference we found was that $24 \%$ of the participants whose parents divorced had never been married, compared with $14 \%$ of the participants from intact families. This pattern was consistent across all age groups.

The effect sizes for the relationships found in this study are fairly small; however, small effects are to be expected in circumstances where the effects are long term, in this case 16 to 50 years (Landerman, George, \& Blazer, 1991). Such events are part of a developmental trajectory in which each contribution is expected to be small but cumulative (Wertlieb, Weigel, Springer, \& Feldstein, 1987). Because this effect is small, it would not be detected consistently without a substantial sample size which may explain why some studies have found no relationship between parental separation and health. Furthermore, only $13 \%$ of the sample experienced parental divorce, so parental divorce could not have explained a large amount of the variance in physical or psychological well-being in the sample even if the differences in the means were larger (Glenn \& Shelton, 1983).

Longitudinal data would be useful to further delineate the pathways between parental death and divorce and well-being in adulthood. Knowledge of the child's early health status and personality would be particularly helpful in determining whether the individual's difficulties were caused by the loss or merely exacerbated by it. However, the results of this study provide suggestive evidence that the impact of parental divorce on adult well-being is through a reduction in both social and economic resources. 
By examining the pathways through which divorce or death impacts well-being in mid-life, we may be able to intervene and help children change negative behaviours and interaction styles before they become long-term problems. However, it is still unclear how parental divorce and death may differentially impact men and women. Therefore, further research is necessary to examine the mechanisms involved in linking childhood experiences of parental divorce and death with health and well-being in later life.

Manuscript received June 1998 Revised manuscript received February 1999

\section{References}

Amato, P.R. (1993). Children's adjustment to divorce: Theories, hypotheses, and empirical support. Journal of Marriage and the Family, 55, 23-38.

Amato, P.R., \& Keith, B. (1991a). Parental divorce and adult well-being: A meta-analysis. Journal of Marriage and the Family, 53, 43-58.

Amato, P.R., \& Keith, B. (1991b). Parental divorce and the well-being of children. A meta-analysis. Psychological Bulletin, 110, 26-46.

Amato, P.R., \& Keith, B. (1991c). Separation from a parent during childhood and adult socioeconomic attainment. Social Forces, 70, 187-206.

Aro, H.M., \& Palosaari, U.K. (1992). Parental divorce, adolescence and transition to adulthood. American Journal of Orthopsychiatry, 62, 421-429.

Baron, R.M., \& Kenny, D.A (1986). The moderator-mediator variable distinction in social psychological research: conceptual, strategic, and statistical considerations. Journal of Personality and Social Psychology, 51, 1173-1182.

Berlinsky, E., \& Biller, H. (1982). Parental death and psychological development. Lexington, MA: D.C. Health.

Bowlby, J. (1977). The making and breaking of affectional bonds: Aetiology and psychopathology in the light of attachment theory. British Journal of Psychiatry, 130, 201-210.

Bowlby, J. (1982). Attachment and loss: Retrospect and prospect. American Journal of Orthopsychiatry, 52, 664-678.

Brown, G.W. (1981). Life events, psychiatric disorder and physical illness. Journal of Psychosomatic Research, 25, 461-473.

Brown, G.W., \& Harris, T.O. (1978). Social origins of depression: A study of psychiatry disorder in women. New York: Free Press.

Clark, R., \& Clifford, T. (1996). Towards a resources and stressors model: The psychological adjustment of adult children of divorce. Journal of Divorce and Remarriage, 25, 105-137.

Dennehy, C.M. (1966). Childhood bereavement and psychiatric illness. British Journal of Psychiatry, 112, 1049-1069.

Doherty, W.J., \& Needle, R.H. (1991). Psychological adjustment and substance use among adolescents before and after a parental divorce. Child Development, $62,328-337$.

Elder, G., George, L.K., \& Shanahan, M.J. (1996). Psychosocial stress over the life course. In H.B. Kaplan (Ed.), Psychosocial stress: Perspectives on structure, theory, life course, and methods (pp. 247-292). Orlando, FL: Academic Press.

Emery, R.E., \& Forehand, R. (1994). Parental divorce and children's well-being: A focus on resilience. In R.J. Haggerty, L.R. Sherrod, N. Garmezy, \& M. Rutter (Eds.), Stress, risk, and resilience in children and adolescents (pp. 64-99). New York: Cambridge University Press.

Glenn, N.D., \& Kramer, K.B. (1985). The psychological well-being of adult children of divorce. Journal of Marriage and the Family, 47, 905-912.
Glenn, N.D., \& Shelton, B.A. (1983). Pre-adult variables and divorce: A note of caution about overreliance on explained variance. Journal of Marriage and the Family, 45, 405-410.

Hetherington, E.M. (1989). Coping with family transitions: Winners, losers, and survivors. Child Development, 60, 1-14.

House, J.S., Umberson, D., \& Landis, K.R. (1988). Structures and processes of social support. Annual Review of Sociology, 14, 293-318.

Keith, V.M., \& Finlay, B. (1988). The impact of parental divorce on children's educational attainment, marital timing, and likelihood of divorce. Journal of Marriage and the Family, 50, 797-809.

Kessler, R.C., Gillis-Light, J., Magee, W.J., Kendler, K.S., \& Eaves, L.J. (1997) Childhood adversity and adult psychopathology. In I.H. Gotlib, \& B. Wheaton (Eds.), Stress and adversity over the life course: Trajectories and turning points (pp. 29-49). New York: Cambridge University Press.

Kessler, R.C., Nelson, C.B., McGonagle, K.A., Edlund, B.S., Frank, R.G., \& Leaf, P.J. (1996). The epidemiology of co-occurring addictive and mental disorders: Implications for prevention and service utilization. American Journal of Orthopsychiatry, 66, 17-31.

Lachman, M.E., \& James, J.B. (1997). Charting the course of midlife development. In M.E. Lachman, \& J.B. James (Eds.), Multiple paths of midlife development (pp. 1-17). Chicago, IL: Univesity of Chicago Press.

Landerman, R., George, L.K., \& Blazer, D.G. (1991). Adult vulnerability for psychiatric disorders: Interactive effects of negative childhood experiences and recent stress. Journal of Nervous and Mental Disease, 179, 656-663.

Marmot, M.G., Kogevinas, M., \& Elston, M.A. (1987). Social/economic status and disease. Annual Review of Public Health, 8, 11-135.

Ragan, P.V., \& McGlashan, T.H. (1986). Childhood parental death and adult psychopathology. American Journal of Psychiatry, 143, 153-157.

Rutter, M. (1990). Psychosocial resilience and protective mechanisms. In J. Rolf, A. Masten, D. Cicchetti, K. Neutchterlein, \& S. Wintraub (Eds.), Risk and protective mechanisms in the development of psychopathology (pp. 181-214). New York: Cambridge University Press.

Rutter, M. (1995). Clinical implications of attachment concepts: Retrospect and prospect. Journal of Child Psychology and Psychiatry, 36, 549-571.

Rutter, M. (1996). Transitions and turning points in developmental psychopathology: As applied to the age span between childhood and mid-adulthood. International Journal of Behavioral Development, 19, 603-626.

Ryff, C. (1989). Happiness is everything, or is it? Explorations on the meaning of psychological well-being. Journal of Personality and Social Psychology, 57, 1069-1081.

Ryff, C., \& Keyes, C.L.M. (1995). The structure of psychological well-being revisited. Journal of Personality and Social Psychology, 62, 719-727.

Schwartz, J.E., Friedman, H.S., Tucker, J.S., Tomlinson-Keasey, C., Wingard, D.L., \& Criqui, M.H. (1995). Sociodemographic and psychosocial factors in childhood as predictors of adult mortality. American Journal of Public Health, $85,1237-1245$.

Tennant, C. (1988). Parental loss in childhood: Its effects in adult life. Archives of General Psychiatry, 45, 1045-1050.

Tucker, J.S., Friedman, H.S., Schwartz, J.E., Criqui, M.H., Tomlinson-Keasey, C., Wingard, D.L., \& Martin, L.R. (1997). Parental divorce: Effects on individual behavior and longevity. Journal of Personality and Social Psychology, 73, 381-391.

Weiss, R. (1979). Growing up a little faster: The experience of growing up in a single parent household. Journal of Social Issues, 35, 97-111.

Wertlieb, D., Weigel, C., Springer, T., \& Feldstein, M. (1987). Temperament as a moderator of children's stressful experiences. American Journal of Orthopsychiatry, 57, 234-245.

Wertlieb, D. (1997). Children whose parents divorce: life trajectories and turning points. In I.H. Gotlib, \& B. Wheaton (Eds.), Stress and adversity over the life course: Trajectories and turning points (pp. 29-49). New York: Cambridge University Press. 